\title{
Age 80 years and over is not associated with increased morbidity and mortality following pancreaticoduodenectomy
}

Sandy Yegi Kim ${ }^{1}$ MD, Michael A. Fink ${ }^{1}$ MD, FRACS, Marcos Perini ${ }^{2}$ PhD, FRACS, Nezor Houli ${ }^{1}$ MBBS, FRACS, Laurence Weinberg ${ }^{2}$ MD, FANZCA, Vijayaragavan Muralidharan ${ }^{1}$ PhD, FRACS, Graham Starkey ${ }^{1}$ MBBS, FRACS, Robert M. Jones ${ }^{1}$ MBBS, FRACS, Christopher Christophi ${ }^{1}$ MD, FRACS, Mehrdad Nikfarjam ${ }^{1}$ PhD, FRACS

University of Melbourne Department of Surgery ${ }^{1}$ and Anaesthesia ${ }^{2}$, Austin Health, Heidelberg, Victoria, Australia.

Key words: Pancreas, Pancreaticoduodenectomy, Octogenarians, Aged 80 or over, Post-operative

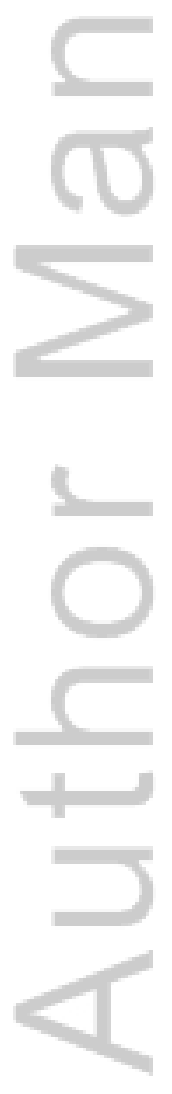
\author{
outcomes \\ Corresponding Author \\ Associate Professor Mehrdad Nikfarjam \\ MD, PhD, FRACS \\ University Department of Surgery \\ Austin Health, LTB 8, \\ Studley Rd, Heidelberg \\ Melbourne, Victoria, 3084 \\ Australia \\ Tel: +61394965466 \\ Fax: +6139458 1650 \\ Email: mehrdad.nikfarjam@gmail.com
}

Abstract Length: 249 Words

Text Length: 2377 words

Number of Figures: 1

Number of Tables: 2

This is the author manuscript accepted for publication and has undergone full peer review but has not been through the copyediting, typesetting, pagination and proofreading process, which may lead to differences between this version and the Version of Record. Please cite this article as doi: 10.1111/ans.14039 


\begin{abstract}
Background: Pancreaticoduodenectomy (PD) is associated with high morbidity which is perceived to be increased in the elderly. To our knowledge there have been no Australian series that have compared outcomes of patients over the age of 80 undergoing PD to those who are younger.
\end{abstract}

Methods: Patients who underwent PD between January 2008 and November 2015 were identified from a prospectively maintained database.

Results: A total of 165 patients underwent PD of whom $17(10.3 \%)$ were aged 80 or over. The pre-operative health status, according to American Society of Anaesthesiologists class was similar between the groups $(\mathrm{p}=0.420)$. The 90 -day mortality rates $(5.9 \%$ in the elderly and $2 \%$ in the younger group; $\mathrm{p}=0.355)$ and the post-operative complication rates $(64.7 \%$ in the elderly versus $62.8 \%$ in the younger group; $p=0.88)$ were similar. Overall median length of hospital stay was also similar between the groups, but older patients were far more likely to be discharged to a rehabilitation facility than younger patients $(47.1 \%$ versus $12.8 \%$; $\mathrm{p}<0.0001)$. Older patients with pancreatic adenocarcinoma $(\mathrm{n}=10)$ had significantly lower median survival than the younger group ( $n=69)$ (16.6 months versus 22.5 months; $p=0.048)$.

Conclusion: No significant differences were seen in the rate of complications following PD in patients aged 80 or over compared to younger patients, although there appears to be a shorter survival in the elderly patients treated for pancreatic cancer. Careful selection of elderly patients and optimal peri-operative care, rather than age should be used to determine whether surgical intervention is indicated in this patient group. 


\section{INTRODUCTION}

The population aged 80 or over is increasing worldwide, constituting around $1 \%$ of the overall population ${ }^{1}$ and is predicted to increase 4-fold by $2050^{1-3}$. This has imposed a new challenge for the healthcare system, given that $70 \%$ of cancer is expected to occur in the elderly. ${ }^{2}$ Pancreatic cancer has an incidence that increases with the age $\mathrm{e}^{1,4}$ and therefore surgical options such as pancreaticoduodenectomy (PD) need to be considered more frequently in the elderly.

In the last two decades, the outcomes of PD have improved with better surgical techniques and optimal postoperative care of patients ${ }^{1}$. Given that pancreatic cancer has a poor prognosis, offering major surgery to elderly patients has been considered controversial. ${ }^{1}$ It is estimated that the 5 -year survival rate after resection of pancreatic cancer is only $12 \%$ to $24 \% .^{5,6,7}$ There are several recent studies from the United States, Germany and Italy ${ }^{1,8,9}$ that have retrospectively analysed data on outcomes of elderly patients treated by PD compared with younger subgroups generally suggesting greater post-operative complications and mortality in the older group. As far as we are aware, there have been no Australian series that have reported on such an outcome that will allow comparisons with other reported literature.

This article is protected by copyright. All rights reserved. 


\section{METHODS}

\section{Patients}

Patients treated at Austin Health, Melbourne, Australia who underwent PD between January 2008 and November 2015 were included in this study. Patients were managed post operatively by standard enhanced recovery techniques. This study was approved by the Austin Health Human Ethics Committee. Follow-up data was complete as of May 2016 for all patients.

\section{Pathology}

The histopathological diagnoses of the resected specimens were identified and categorised into benign and malignant lesions. Pancreatic ductal adenocarcinoma (PDAC) was the most common malignant tumour treated. A microscopic positive margin (R1) was defined as the presence of tumour at any inked surgical margin at the time of histological examination.

\section{Preoperative Assessment}

Patients' demographic information was recorded including age, sex, body mass index, American Society of Anesthesiologists (ASA) classification and pre-morbid conditions.

\section{Operative Details}

Information including operative technique, duration of surgery, estimated blood loss, intra-operative blood transfusion and use of epidural or intrathecal morphine were recorded.

\section{Post-operative Outcome}

Post-operative outcomes such as morbidity, mortality, length of hospital stay, length of intensive care unit (ICU) stay, re-operation and hospital readmissions within 90 days after discharge were recorded. 


\section{Complications and severity}

Patient complications were recorded and the severity of post-operative complications were analysed using Comprehensive Complication Index (CCI) calculator as previously described, ${ }^{10}$ utilising an online calculator (http://www.assessurgery.com/about_cci-calculator/). Post-operative complications were further categorised into general and PD-specific. Delayed gastric emptying (DGE), post-operative pancreatic fistula (POPF) and haemorrhage were defined using the International Study Group of Pancreatic Surgery criteria ${ }^{11}$ 12.

\section{Statistical Analysis}

All the statistical analyses were performed using SPSS (IBM SPSS Statistics Version 22). Categorical variables were assessed using the chi-squared or Fisher's exact test. Comparisons of continuous data were performed with the use of Student's t test for normally distributed data, otherwise the Mann-Whitney U test was used. Values were reported as mean and standard deviation or median with range. Kaplan-Meier method was used to create survival curves which were then compared using a univariate Log-rank test. Statistical significance was considered when $p$-value $<0.05$.

\section{RESULTS}

\section{Patients}

The patient characteristics are shown in Table 1. There were 165 patients who underwent PD of which 17 (10.3\%) patients who were aged 80 or over. The two groups did not show differences in ASA classifications $(\mathrm{p}=0.420)$, but the older group was far more likely to be hypertensive pre-operatively [Odds Ratio (OR) 3.2, 95\% Confidence Interval (CI):1.09-9.66, $\mathrm{p}=0.028]$. Significantly more patients in the older group $(76.5 \%)$ underwent biliary stent insertion pre-operatively than the younger group $(44.6 \%)(\mathrm{p}=0.019)$. This may be partly related to a greater proportion of PDAC cases (Table S1) or anticipated delays to surgery. Our unit generally avoids biliary stenting prior to surgery, when timely access to operative sessions are available and bilirubin levels are below $200 \mu \mathrm{mol} / \mathrm{L}$. 


\section{Pathology}

Pathology details are noted in Table S1. The majority of elderly patients with malignant diseases had PDAC (71.4\%), with similar nodal and R1 status as their younger counterparts.

\section{Operative Details}

There was no difference between younger and older patients in terms of duration of surgery, intra-operative blood loss, intra-operative blood transfusion, use of epidural and intrathecal analgesia, reported pancreatic texture or pancreatic duct diameter (Table S2).

\section{Mortality}

One patient died within 90 -days of surgery in the elderly group (5.9\%) compared to $3(2 \%)$ in the younger group with no statistical difference between the two groups $(\mathrm{p}=0.355)($ Table 2$)$.

\section{Post-operative complications}

Post-operative complications were compared between the two groups as Table 2 shows. The overall complications were similar in the two populations $(\mathrm{p}=0.88)$.

\section{PD-specific complications}

No differences were found in PD-specific complications, as shown in Table 2.

\section{Length of Stay}

The median length of hospital stay for the older population was 15 days and that of the younger population was 12 days, which was not significantly different $(\mathrm{p}=0.162)($ Table S3) 


\section{Discharge}

There was a significant difference in the discharge destinations between the two groups (Table S3). In total, $47.1 \%$ of older patients were discharged to rehabilitation facilities whereas this was required in only $12.8 \%$ of younger patients $(\mathrm{p}<0.0001)$.

\section{Survival}

At follow-up, there were $10(58.8 \%)$ patients deceased in the older cohort and $60(40.5 \%)$ deaths in the younger group $(\mathrm{p}=0.078)$ (Table 2$)$. The majority of deaths were related to malignant disease recurrence. The median survival in patients aged 80 or over was 19.1 months which was not significantly lower than younger patients at 61.1 months, $\mathrm{p}=0.067$. The 1-, 3-, and 5-year survival rates were $82.4 \%, 27.9 \%$ and $27.9 \%$, respectively, in the older group and $80.8 \%, 59.1 \%$ and $51.8 \%$, respectively, in the younger group (p $=0.067)($ Figure $1 \mathrm{~A})$.

At the time of follow-up $80.0 \%$ of the older group with PDAC were deceased compared with $59.4 \%$ of younger patients with PDAC, $\mathrm{p}=0.210$. Among these patients, cancer recurrence was noted in $87.5 \%$ of patients in the older group and $70 \%$ in the younger cohort, $\mathrm{p}=0.081$ (Table 2 ). The adjuvant chemotherapy treatment rates were similar between the groups $6(60 \%)$ in the older group versus $48(69.6 \%)$ in the younger group; $\mathrm{p}=0.543$ ). Patients in the older group with PDAC had a median survival of 16.6 months, compared with 22.5 months in the younger group $(\mathrm{p}=0.048)$. The survival rate in the older group at 1 -year was $80.0 \%$, with no 3-year or 5-year survivors. This is compared to a 1-year survival of 71.4\%, 3-year 37.4\%, 5-year $27.6 \%$ for those in the younger group $(p=0.048)$ (Figure $1 B)$.

This article is protected by copyright. All rights reserved. 


\section{DISCUSSION}

PD can improve quality of life and is the only potentially curative option for peri-ampullary or pancreatic malignancy. ${ }^{13} \mathrm{PD}$ is however associated with a high morbidity ranging from $41 \%$ to $52 \%$ in some large series $^{14,6,15}$ with a reluctance of offering surgery in some centres to older patients. Despite improved operative techniques and low post-operative mortality, the rate of post-operative morbidity remains high. Our study showed the rates of post-operative complications at $64 \%$ in elderly and $62 \%$ in younger patients, which were statistically similar between the two populations. Even though there is a high rate of complications, the vast majority of patients have these detected early and treated successfully to prevent mortality.

The PD-specific complications that impact patient outcomes include POPF, DGE, bile leakage and haemorrhage ${ }^{11,16}$. Risk factors for developing POPF include soft texture of the pancreas and the size of the pancreatic duct. It has been shown previously that the age has no effect on the incidence of POPF. ${ }^{3}$ This finding is consistent with our results where none of the elderly patients developed POPF. DGE is another potential PD-specific complication which was reported to be increased in the elderly population in some series, ${ }^{1,6}$ possibly due to global reduction in gastrointestinal motility in elderly patients. ${ }^{17}$ It is, however, inconsistent across the reported literature, ${ }^{18,19}$ possibly related to differences in the definitions used. With regard to other PD-specific complications such as delayed gastric emptying, bile leakage and haemorrhage, we found no differences between our groups, which are in keeping with other published reports. ${ }^{3,19}$

The median length of hospital stay was not significantly different between the elderly and the younger cohorts, which may be reflective of similar post-operative complication rates in each of the groups. The median length of hospital stay in our study in elderly patients was comparable to large United States series of PD, possibly reflecting our utilisation of enhanced recovery pathways. ${ }^{6,}{ }^{20}$ Johns Hopkins Medical Centre showed a decline in the length of stay in patients from 21 days to 10 days ${ }^{20}$ with more streamlined post- 
operative care. It should however be noted that elderly patients were far more likely to be discharged to a rehabilitation facility than home. This finding is consistent with other reported series. ${ }^{21,22}$ A study conducted at Mayo Clinic $^{23}$ noted that despite the increased need for rehabilitation in the elderly population following PD, the patients were mostly independent in their ambulatory status and were discharged to home after generally a short period at the rehabilitation facilities.

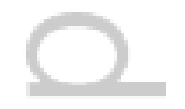

Other studies have reported higher mortality associated with PD in patients aged 80 years and older, often reflecting a higher ASA status. ${ }^{1,6}$ This was not the case in our study and may reflect the similar preoperative medical status of the patients based on ASA score. Although our unit does not use age per se when determining whether to offer PD, it is possible that many elderly patients with perceived major comorbidities were excluded from surgery, which we were unable to identify due to the retrospective nature of this study. There were no standard pre-operative objective tests routinely used to assess patient's fitness for surgery in our unit. Cardiorespiratory function testing was undertaken selectively. We could not determine the absolute number patients with potentially resectable tumours who were not offered surgery due a perceived lack of fitness. In addition, it is probable that some elderly patients with a diagnosis of pancreatic cancer may not be referred to our unit for consideration of surgery due to primary physician biases.

The long-term survival of patients undergoing PD aged 80 years and older compared to younger patients has been analysed in a limited number of series. ${ }^{15,24}$ There appear to be major variations in survival following PD in the published literature which may be related to the inclusion of different pathologies in the analysis. ${ }^{18,}$ ${ }^{25}$ In our study, the overall survival was significantly decreased in the older cohort treated by PDAC compared to younger patients. This included a small number of patients, but the tumour staging was similar between the two groups. There is some suggestion that the tumour biology in the elderly patients may be more aggressive for unknown reasons. ${ }^{26}$ Comparison of survival in elderly populations with resectable tumour treated by palliative chemotherapy compared to surgical resection would provide further insights. 
This could not however be undertaken from the data available to us for this study. A reduction in the survival in older patients may also relate to age-related predicted lower life expectancy in those aged 80 years and older. The general population's life expectancy in Australia is trending up and men and women aged 80 or over are expected to live for another 10 years, ${ }^{27}$ while the life expectancy in people aged 65 is double that of those 80 years and over. ${ }^{27,28}$.Nevertheless, given the life expectancy of up to 10 or more years in the octogenarian or older population, consideration for surgery appears a valid option in highly selected patients operated on by experienced surgeons in tertiary hospitals. The median survival of 16.6 months in patients over the age of 80 years undergoing PD for treatment of pancreatic cancer appears to be better that those of patients with non-metastatic pancreatic cancer treated by chemotherapy alone. ${ }^{29}$

\section{CONCLUSION}

In a large Australian series of PD, $10 \%$ of those offered surgery were aged 80 years or older and had similar comorbidities to younger patients. The overall post-operative morbidity, mortality, ICU and hospital stay was similar between the two groups. The older patients were, however, more likely to require rehabilitation following surgery. Long-term survival was lower in the older patients treated for pancreatic cancer, which may reflect disease biology and inherent lower life-expectancy with increasing age, rather than being directly related to surgical factors. Careful selection of patients aged 80 or over for PD appears be the major determinant of surgical outcomes rather than the patients' age alone. Therefor older patients should not be excluded from surgical intervention solely due to their age. 
LEGENDS

\section{Figure 1}

Kaplan-Meier survival curve for patients undergoing pancreaticoduodenectomy. A. The overall survival rates for those aged 80 years and over $(n=17)$ were not statistically significantly different to the younger patients $(\mathrm{n}=148)(\mathrm{p}=0.067)(\log -\mathrm{Rank}$ Test $)$ B. In patients with pancreatic ductal adenocarcinoma the survival rate for those aged 80 years and over $(n=10)$ and was significantly less than the younger patients $(\mathrm{n}=69)(\mathrm{p}=0.048)(\log -$ Rank Test $)$

This article is protected by copyright. All rights reserved. 


\section{ACKNOWLEGEGMENTS}

The authors would like to acknowledge the contribution of Mr Jude Mukkadayil, for maintaining the prospective surgical database that was accessed for this study and Ms Rebecca Dimovitis (RN) for her assistance in collecting some additional patient data. We also acknowledge Pancare Foundation (www.pancare.org.au) for providing pancreatic cancer research funding support.

This article is protected by copyright. All rights reserved. 


\section{REFERENCES}

[1] Belyaev O, Herzog T, Kaya G, et al. Pancreatic surgery in the very old: face to face with a challenge of the near future. World J Surg. 2013; 37:1013-20.

[2] Langan RC, Huang CC, Mao WR, et al. Pancreaticoduodenectomy hospital resource utilization in octogenarians. Am J Surg. 2016; 211:70-5.

[3] Tani M, Kawai M, Hirono S, et al. A pancreaticoduodenectomy is acceptable for periampullary tumors in the elderly, even in patients over 80 years of age. J Hepatobiliary Pancreat Surg. 2009; 16:675-80. [4] Australia AGC. Pancreatic Cancer in Australia. Edition., cited 22 August 2015].Available from: http://canceraustralia.gov.au/affected-cancer/cancer-types/pancreatic-cancer/pancreatic-cancer-

\section{$\underline{\text { statistics\#inca }}$}

[5] Hardacre JM, Simo K, McGee MF, Stellato TA, Schulak JA. Pancreatic resection in octogenarians. $J$ Surg Res. 2009; 156:129-32.

[6] Makary MA, Winter JM, Cameron JL, et al. Pancreaticoduodenectomy in the very elderly. $J$ Gastrointest Surg. 2006; 10:347-56.

[7] Beltrame V, Gruppo M, Pastorelli D, Pedrazzoli S, Merigliano S, Sperti C. Outcome of pancreaticoduodenectomy in octogenarians: Single institution's experience and review of the literature. $J$ Visc Surg. 2015; 152:279-84.

[8] Langan RC, Zheng C, Harris K, Verstraete R, Al-Refaie WB, Johnson LB. Hospital-level resource use by the oldest-old for pancreaticoduodenectomy at high-volume hospitals. Surgery. 2015; 158:366-72. [9] Gangl O, Froschl U, Fugger R. Surgical quality data and survival after pancreatic cancer resections: a comparison of results for octogenarians and younger patients. Wien Klin Wochenschr. 2014; 126:757-61. [10] Slankamenac K, Nederlof N, Pessaux P, et al. The comprehensive complication index: a novel and more sensitive endpoint for assessing outcome and reducing sample size in randomized controlled trials. Ann Surg. 2014; 260:757-62; discussion 62-3.

[11] Bassi C, Dervenis C, Butturini G, et al. Postoperative pancreatic fistula: an international study group (ISGPF) definition. Surgery. 2005; 138:8-13. 
[12] Wente MN, Bassi C, Dervenis C, et al. Delayed gastric emptying (DGE) after pancreatic surgery: a suggested definition by the International Study Group of Pancreatic Surgery (ISGPS). Surgery. 2007; $142: 761-8$

[13] Crippa S, Dominguez I, Rodriguez JR, et al. Quality of life in pancreatic cancer: analysis by stage and treatment. J Gastrointest Surg. 2008; 12:783-93; discussion 93-4.

[14] Gooiker GA, van Gijn W, Wouters MW, et al. Systematic review and meta-analysis of the volumeoutcome relationship in pancreatic surgery. Br J Surg. 2011; 98:485-94.

[15] Lee MK, Dinorcia J, Reavey PL, et al. Pancreaticoduodenectomy can be performed safely in patients aged 80 years and older. J Gastrointest Surg. 2010; 14:1838-46.

[16] Sukharamwala P, Thoens J, Szuchmacher M, Smith J, DeVito P. Advanced age is a risk factor for post-operative complications and mortality after a pancreaticoduodenectomy: a meta-analysis and systematic review. HPB (Oxford). 2012; 14:649-57.

[17] Shimamoto C, Hirata I, Hiraike Y, Takeuchi N, Nomura T, Katsu K. Evaluation of gastric motor activity in the elderly by electrogastrography and the (13)C-acetate breath test. Gerontology. 2002; 48:381-6. [18] Hatzaras I, Schmidt C, Klemanski D, et al. Pancreatic resection in the octogenarian: a safe option for pancreatic malignancy. J Am Coll Surg. 2011; 212:373-7.

[19] Oguro S, Shimada K, Kishi Y, Nara S, Esaki M, Kosuge T. Perioperative and long-term outcomes after pancreaticoduodenectomy in elderly patients 80 years of age and older. Langenbecks Arch Surg. 2013; 398:531-8.

[20] Cameron JL, He J. Two thousand consecutive pancreaticoduodenectomies. J Am Coll Surg. 2015; 220:530-6.

[21] Dale W, Hemmerich J, Kamm A, et al. Geriatric assessment improves prediction of surgical outcomes in older adults undergoing pancreaticoduodenectomy: a prospective cohort study. Ann Surg. 2014; 259:960-5.

[22] Riall TS, Reddy DM, Nealon WH, Goodwin JS. The effect of age on short-term outcomes after pancreatic resection: a population-based study. Ann Surg. 2008; 248:459-67. 
[23] Khan S, Sclabas G, Lombardo KR, et al. Pancreatoduodenectomy for ductal adenocarcinoma in the very elderly; is it safe and justified? J Gastrointest Surg. 2010; 14:1826-31.

[24] Sohn TA, Yeo CJ, Cameron JL, et al. Should pancreaticoduodenectomy be performed in octogenarians? J Gastrointest Surg. 1998; 2:207-16.

[25] Melis M, Marcon F, Masi A, et al. The safety of a pancreaticoduodenectomy in patients older than 80 years: risk vs. benefits. $H P B$ (Oxford). 2012; 14:583-8.

[26] M Brigden LB. Followup reccomendations Part 9. Oncology Exchange. 2016; 15.

[27] Welfare AIoHa. Life Expectancy Edition. Australia, cited 1st June 2016].Available from: http://www.aihw.gov.au/deaths/life-expectancy/

[28] Huo L, Shaw JE, Wong E, Harding JL, Peeters A, Magliano DJ. Burden of diabetes in Australia: life expectancy and disability-free life expectancy in adults with diabetes. Diabetologia. 2016; 59:1437-45. [29] Gillen S, Schuster T, Meyer Zum Buschenfelde C, Friess H, Kleeff J. Preoperative/neoadjuvant therapy in pancreatic cancer: a systematic review and meta-analysis of response and resection percentages. PLoS Med. 2010; 7:e1000267.

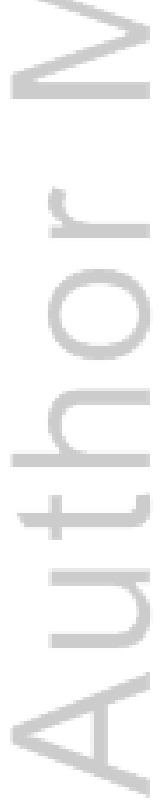

This article is protected by copyright. All rights reserved. 

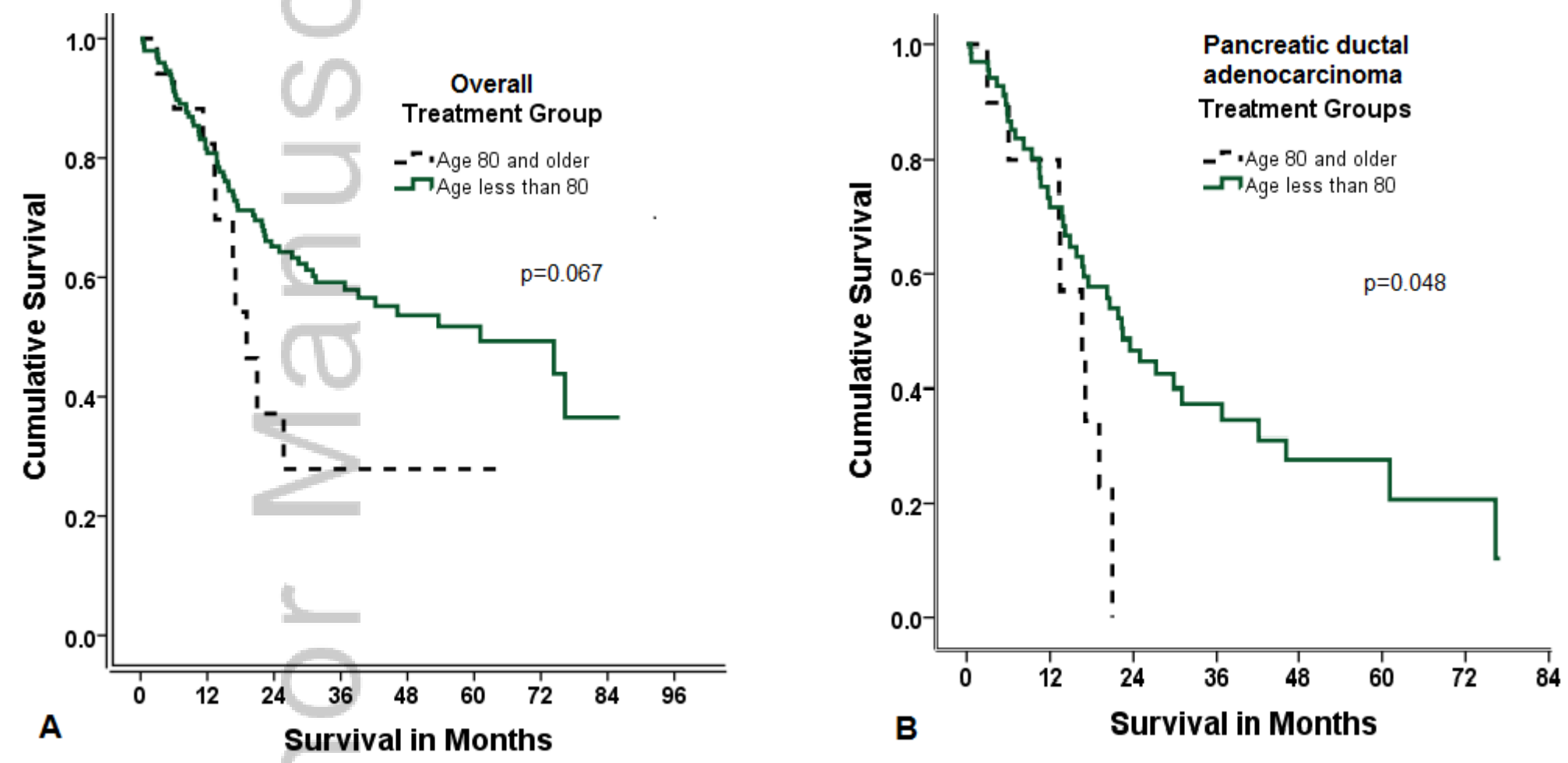

Fig 1.tif

This article is protected by copyright. All rights reserved. 
Table 1. Clinicopathological and surgical characteristics of patients treated by pancreaticoduodenectomy according to age group. Data are displayed as number (\%), median (range) or mean \pm standard deviation.

\begin{tabular}{|c|c|c|c|}
\hline & $\begin{array}{c}\text { e } 80 \text { years old } \\
(n=17)\end{array}$ & $\begin{array}{c}<80 \text { years old } \\
(\mathrm{n}=148)\end{array}$ & P-value \\
\hline Sex (Male) & $9(52.9 \%)$ & $82(55.4 \%)$ & 0.847 \\
\hline Age & $81(80-86)$ & $66(15-79)$ & $<0.0001$ \\
\hline $\mathrm{BMI}^{\mathrm{a}}$ & $24.2 \pm 0.7$ & $25.7 \pm 0.5$ & 0.059 \\
\hline $\begin{array}{c}\text { ASA }^{\mathrm{b}} \text { Class I } \\
\\
\text { II } \\
\text { III } \\
\text { IV }\end{array}$ & $\begin{array}{c}0(0.0 \%) \\
2(11.8 \%) \\
15(88.2 \%) \\
0(0 \%)\end{array}$ & $\begin{array}{c}5(3.4 \%) \\
36(24.3 \%) \\
103(69.6 \%) \\
4(2.7 \%)\end{array}$ & 0.420 \\
\hline History of Pancreatitis & $1(5.9 \%)$ & $24(16.2 \%)$ & 0.260 \\
\hline Diabetes Mellitus & $5(29 \%)$ & $40(27 \%)$ & 0.834 \\
\hline Hypertension & $12(70.6 \%)$ & $63(42.6 \%)$ & *0.028 \\
\hline Ischaemic Heart Disease & $5(29.4 \%)$ & $18(12.2 \%)$ & 0.052 \\
\hline $\mathrm{COPD}^{\mathrm{c}}$ & $1(5.9 \%)$ & $13(8.8 \%)$ & 0.684 \\
\hline Chronic Renal Failure & $1(5.9 \%)$ & $6(4.1 \%)$ & 0.723 \\
\hline Pre-operative stent insertion & $13(76.5 \%)$ & $66(44.6 \%)$ & *0.019 \\
\hline \multicolumn{4}{|c|}{ Pre-operative Laboratory Tests } \\
\hline Haemoglobin, g/L & $121.4 \pm 12.2$ & $124.0 \pm 28.9$ & 0.103 \\
\hline White Cell Count, $\times 10^{9} / \mathrm{L}$ & $8.6 \pm 3.4$ & $7.9 \pm 3.7$ & 0.854 \\
\hline Platelets, $\times 10^{9} / \mathrm{L}$ & $299.3 \pm 124.4$ & $296.0 \pm 106.5$ & 0.998 \\
\hline Bilirubin, $\mu \mathrm{mol} / \mathrm{L}$ & $47.1 \pm 84.7$ & $58.8 \pm 94.8$ & 0.615 \\
\hline Albumin, $\mathrm{g} / \mathrm{L}$ & $33.1 \pm 9.6$ & $36.3 \pm 8.1$ & 0.250 \\
\hline Urea, $\mathrm{mmol} / \mathrm{L}$ & $6.9 \pm 3.0$ & $5.6 \pm 2.43$ & 0.616 \\
\hline Creatinine, $\mu \mathrm{mol} / \mathrm{L}$ & $85.6 \pm 33.8$ & $74.0 \pm 28.3$ & 0.163 \\
\hline \multicolumn{4}{|l|}{ Types of Operation } \\
\hline Pylorus preserving & $3(17.6 \%)$ & $33(22.3 \%)$ & \multirow[t]{2}{*}{0.660} \\
\hline Non-pylorus preserving & $14(82.4 \%)$ & $115(77.7 \%)$ & \\
\hline \multicolumn{4}{|l|}{ Portal vein resection } \\
\hline Partial/total & $2(11.8 \%)$ & $19(12.8 \%)$ & 0.900 \\
\hline
\end{tabular}

${ }^{\mathrm{a}} \mathrm{BMI}=$ Body Mass Index ${ }^{\mathrm{b}} \mathrm{ASA}=$ American Society of Anaesthesiologist

${ }^{\mathrm{c}} \mathrm{COPD}=$ Chronic Obstructive Pulmonary Disease 
Table 2. Post-operative outcomes of patients treated by pancreaticoduodenectomy according to age group.

\begin{tabular}{|c|c|c|c|}
\hline & $\begin{array}{c}\text { e80 years old } \\
(\mathrm{n}=17)\end{array}$ & $\begin{array}{c}<80 \text { years old } \\
(\mathrm{n}=148)\end{array}$ & P-value \\
\hline Any complication & $11(64.7 \%)$ & $93(62.8 \%)$ & 0.880 \\
\hline Myocardial infarction & $1(5.9 \%)$ & $4(2.7 \%)$ & 0.469 \\
\hline Arrhythmia & $5(29.4 \%)$ & $20(13.5 \%)$ & 0.083 \\
\hline Acute pulmonary oedema & $2(11.8 \%)$ & $8(5.4 \%)$ & 0.298 \\
\hline Pneumonia & $2(11.8 \%)$ & $12(8.8 \%)$ & 0.686 \\
\hline Acute renal failure & $0(0.0 \%)$ & $7(4.7 \%)$ & 0.359 \\
\hline Urinary tract infection & $0(0.0 \%)$ & $3(2.0 \%)$ & 0.554 \\
\hline Wound infection & $3(17.6 \%)$ & $16(10.8 \%)$ & 0.403 \\
\hline Sepsis & $2(11.8 \%)$ & $13(8.8 \%)$ & 0.686 \\
\hline Peritonitis & $0(0.0 \%)$ & $2(1.4 \%)$ & 0.630 \\
\hline Confusion/delirium & $1(5.9 \%)$ & $9(6.1 \%)$ & 0.974 \\
\hline Re-operation & $0(0.0 \%)$ & $9(6.1 \%)$ & 0.296 \\
\hline Re-admission & $4(23.5 \%)$ & $24(16.2 \%)$ & 0.447 \\
\hline PD-Specific Complications & e80 $(n=17)$ & $<80(\mathrm{n}=148)$ & P-value \\
\hline Delayed gastric emptying & $0(0.0 \%)$ & $14(9.5 \%)$ & 0.185 \\
\hline $\mathrm{POPF}^{\mathrm{a}} /$ Leak & $0(0.0 \%)$ & $11(7.4 \%)$ & 0.245 \\
\hline Haemorrhage & $0(0.0 \%)$ & $8(5.4 \%)$ & 0.326 \\
\hline Bile leak & $0(0.0 \%)$ & $7(4.7 \%)$ & 0.359 \\
\hline Complications scoring & $\mathrm{e} 80(\mathrm{n}=11)$ & $<80(n=93)$ & P-value \\
\hline $\begin{array}{l}\text { Clavien-Dindo classification } \\
\text { I } \\
\text { II } \\
\text { III } \\
\text { IV } \\
\text { V } \\
\end{array}$ & $\begin{array}{l}0(0 \%) \\
8(72.7 \%) \\
0(0 \%) \\
3(27.3 \%) \\
0(0 \%) \\
\end{array}$ & $\begin{array}{c}4(4.3 \%) \\
64(68.8 \%) \\
18(19.4 \%) \\
5(5.4 \%) \\
2(2.2 \%) \\
\end{array}$ & 0.061 \\
\hline $\begin{array}{l}\text { CCI }^{\mathrm{e}} \text { score } \\
\text { Mean }^{\text {S } \operatorname{Std}^{\mathrm{f}}}\end{array}$ & $33.4 \pm 15.3$ & $35.8 \pm 17.0$ & 0.878 \\
\hline 90-Day Mortality & $1(5.9 \%)$ & $3(2 \%)$ & 0.355 \\
\hline Mortality at follow-up & $10(58.8 \%)$ & $60(40.5 \%)$ & 0.078 \\
\hline $\begin{array}{l}\text { Mortality at follow-up in } \\
\text { Patients with PDAC }\end{array}$ & $\begin{array}{c}\text { e } 80(n=8 \text { of } 10) \\
80 \%\end{array}$ & $\begin{array}{c}<80(\mathrm{n}=41 \text { of } 69) \\
59.4 \%\end{array}$ & 0.210 \\
\hline Recurrence at time of death & $7(87.5 \%)$ & $25(70 \%)$ & 0.081 \\
\hline
\end{tabular}

${ }^{\mathrm{a}} \mathrm{POPF}=$ Post-operative pancreatic fistula, ${ }^{\mathrm{e}} \mathrm{CCI}=$ Comprehensive Complication Index score, ${ }^{\mathrm{f}} \mathrm{Std}=$ Standard deviation 


\section{University Library}

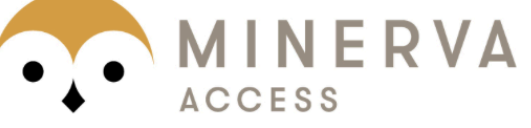

A gateway to Melbourne's research publications

Minerva Access is the Institutional Repository of The University of Melbourne

Author/s:

Kim, SY;Fink, MA;Perini, M;Houli, N;Weinberg, L;Muralidharan, V;Starkey, G;Jones,

RM;Christophi, C;Nikfarjam, M

Title:

Age 80 years and over is not associated with increased morbidity and mortality following pancreaticoduodenectomy

Date:

2018-05-01

Citation:

Kim, S. Y., Fink, M. A., Perini, M., Houli, N., Weinberg, L., Muralidharan, V., Starkey, G., Jones, R. M., Christophi, C. \& Nikfarjam, M. (2018). Age 80 years and over is not associated with increased morbidity and mortality following pancreaticoduodenectomy. ANZ JOURNAL OF SURGERY, 88 (5), pp.E445-E450. https://doi.org/10.1111/ans. 14039.

Persistent Link:

http://hdl.handle.net/11343/293005 